\title{
Microplate magnetic chemiluminescence immunoassay for detecting urinary survivin in bladder cancer
}

\author{
YANLI CHANG, JIANJUN XU and QINGYUN ZHANG \\ Department of Clinical Laboratory, Key Laboratory of Carcinogenesis and Translational Research, Ministry \\ of Education, Peking University Cancer Hospital and Institute, Beijing 100142, P.R. China
}

Received February 13, 2017; Accepted July 20, 2017

DOI: 10.3892/ol.2017.6675

\begin{abstract}
Survivin is a tumor marker for bladder cancer; however the role of urinary survivin levels has not been fully elucidated due to the limitations of current detection methods. Based on two survivin-specific monoclonal antibodies (McAbs) already confirmed through enzyme linked immunosorbent assays, the present study aimed to establish a microplate magnetic chemiluminescence immunoassay (CLIA) for the detection of urinary survivin levels and evaluate its application for the diagnosis of patients with bladder cancer. Horseradish peroxidase and biotin conjugates were used to label two different anti-survivin McAbs, respectively. The labeled antibodies combined with survivin to form a sandwiched immune complex. The streptavidin magnetic particles (MPs) served as the solid phase and the separator. The relevant parameters involved in the immunoassay, including the immunoassay reagents used and the physicochemical parameters were optimized. Then, urine samples from 130 patients with bladder cancer and 113 healthy controls were detected, and analyzed using the established method. The method was linear to $1,000 \mathrm{ng} / \mathrm{ml}$ survivin with a detection limit of $0.83 \mathrm{ng} / \mathrm{ml}$. The intra- and inter-assay coefficients of variation were $<8$, and $<11 \%$, respectively. The concentration of diluted survivin and the dilution ratios gave a linear correlation of 0.9989 . The results demonstrated that the urinary survivin levels in patients with bladder cancer were significantly higher $(\mathrm{P}<0.001)$ compared with that in healthy controls. At a survivin concentration of $2.0884 \mathrm{ng} / \mathrm{ml}$, the sensitivity and specificity were 86.9 and $61.9 \%$, respectively. Furthermore, the urinary survivin levels were positively correlated with metastatic stage, histological stage and recurrence $(\mathrm{P}<0.01)$. In conclusion, the present study preliminarily proposed a microplate magnetic
\end{abstract}

Correspondence to: Dr Qingyun Zhang, Department of Clinical Laboratory, Key Laboratory of Carcinogenesis and Translational Research, Ministry of Education, Peking University Cancer Hospital and Institute, 52 Fucheng Road, Haidian, Beijing 100142, P.R. China E-mail: zhqy_208@163.com

Key words: microplate magnetic chemiluminescence immunoassay, survivin, bladder cancer, tumor markers
CLIA for survivin detection and further evaluated the value of urinary survivin as a diagnostic marker for bladder cancer.

\section{Introduction}

Bladder cancer, the most common malignancy of the urinary tract and the seventh most prevalent cancer worldwide (1), is diagnosed based on the combination of urethrocystoscopy and voided urine cytology (2). While voided urine cytology has an extremely low sensitivity (3) considering its dependence on tumor grades, what makes urethrocystoscopy the 'golden standard' for the screening and follow-up of bladder cancer patients (2). However, the procedure of urethrocystoscopy is invasive and discomfort for patients. Therefore, it is important to develop better non-invasive detection methods for the early diagnosis of bladder cancer (4). Several urinary tests including Bladder tumor antigen (BTA) and Nuclear matrix protein-22 (NMP-22) have been approved by FDA (5). Recently additional possible urinary biomarkers have been investigated (6) including Cyfra 21-1 (7), Matrix metalloproteinase-7 (MMP-7) (8) as well as survivin.

Survivin, a $16.5 \mathrm{kDa}$ protein, is one member of the inhibitor of apoptosis protein (IAP) family and has a unique role in apoptosis and control of cell division (9-11). Survivin is expressed in various tumors while in normal adults it is only expressed in tissues as thymus, endothelium and placenta (12-14). Given its differential expression between normal and tumor tissues, survivin is considered to be a unique marker for the diagnosis of cancer. Studies have shown that survivin is associated with poor prognosis in certain kinds of tumors including bladder cancer $(15,16)$. In bladder cancer, survivin is expressed in epithelium and its expression could be detected by immunohistochemistry (IHC). What's more, as a malignancy of the urinary tract, survivin is expressed in urine that could be detected at the protein and mRNA levels (17). Certain studies found that the measurement of survivin mRNA in urine seemed to perform better than voided urine cytology (15). Recent increasing attention has been focused on the value of urinary survivin detection in bladder cancer, while its clinical utility still remains to be elucidated partly due to the limitation of detection methods.

ELISA method is considered accurate and reliable, which has also been used for the detection of urinary survivin $(18,19)$. But the assay is time consuming with poor reproducibility. 
Thus alternative methods with better performance are needed. Chemiluminescence immunoassay (CLIA) is a much more effective measurement with the advantages of high sensitivity, uniformity and broad dynamic range $(20,21)$. In this study, we tried to develop a microplate magnetic CLIA with two anti-survivin monoclonal antibodies (McAbs) prepared by our laboratory. Besides, in order to evaluate the potential application of the established method, urinary survivin levels of bladder cancer patients and healthy controls were examined.

\section{Materials and methods}

Animals. Female Balb/c mice weighing 18-22 g were purchased from the Laboratory Animal Centre of Chinese Academy of Medical Sciences. The Animal Care Committee of Peking University approved the animal experiments. We performed animal studies in accordance with the Experimental Animal Management Ordinance approved by the Scientific and technological committee of China.

Apparatus. Protein-A/G sepharose (HiTrap Protein G HP, $1 \mathrm{ml}$ ) was purchased from GE Healthcare Life Sciences (Buckinghamshire, UK). ALC-B6 peristaltic pump was purchased from Alcott Biotech Co., Ltd. (Shanghai, China). The chemiluminescence detection was carried out using SpectraMax L microplate reader from Molecular Devices, LLC (Sunnyvale, CA, USA). The IKA ${ }^{\circledR}$ MS3 Digital (Staufen, Germany) was employed to blend the solutions in microplates. The incubation procedure at $37^{\circ} \mathrm{C}$ was carried out at an electric heat constant temperature incubator. The white opaque 96-well flat-bottomed microplates were from Thermo Fisher Scientific (Waltham, MA, USA). A magnetic separation device for 96-well microplate purchased from Beaver Beads Co., Ltd. (Suzhou, China) was used for the separation procedure.

Chemicals and solutions. Incomplete freund's adjuvant (IFA), PEG, horseradish peroxidase (HRP; H1759), sodium borohydride $\left(\mathrm{NaBH}_{4} ; 10 \mathrm{H} 3440\right)$, sodium m-periodate $\left(\mathrm{NaIO}_{4}\right)$ (38F-0860) and (+)-biotin-N-hydroxysuccinimide (NHSB) (HMBD0595 V) were from Sigma-Aldrich Co. (St. Louis, MO, USA). Hypoxanthine-aminopterin-thymidine (HAT) and hypoxanthine-thymidine (HT) were from Corning Inc. (Corning, NY, USA). BCA protein assay kit was obtained from Thermo Fisher Scientic. Chemiluminescent (CL) substrates were purchased from Ke Yue Zhong Kai Co., Ltd. (Beijing, China). The magnetic particles (MPs, $10 \mathrm{mg} / \mathrm{ml}$ ) coated with streptavidin and suspended in solution were purchased from Beaver Beads Co., Ltd. Phosphate-buffered saline (PBS) buffer and bovine serum albumin (BSA) were from ZSGB-Bio (Beijing, China). The washing buffer was PBS containing $0.05 \%(\mathrm{v} / \mathrm{v})$ Tween-20 (PBST). PBST containing 1\% (w/v) BSA served as dilution buffer for HRP-labeled antibody, biotinylated antibody and standard series. The microplates were pre-coated with $300 \mu 11 \%(\mathrm{w} / \mathrm{v}) \mathrm{BSA}$ in PBS buffer at $4^{\circ} \mathrm{C}$ for $12 \mathrm{~h}$ and washed three times before use.

Generation of hybridoma cell lines. The mouse was immunized with $150 \mu \mathrm{g}$ purified recombinant human sequence survivin protein $\mathrm{MS}_{2}$-survivin and the same volume of IFA every two weeks until the serum antibody titer was up to $1: 10,000$. Then $150 \mu \mathrm{g} \mathrm{MS}_{2}$-survivin was administered into the intra-peritoneal cavity without IFA as the final immunogen boost, 3 days before mice's spleen was harvested for cell fusion. Isolated splenocytes were mixed with myeloma cells at the ratio of 10:1 with the presence of polyethylene glycol (PEG) and HAT medium. Six to eight days passed and hybrid colonies survived. The colonies were screened by ELISA with $\mathrm{MS}_{2}$-survivin and $\mathrm{MS}_{2}$-PAI for three times. Positive clonal cells were transferred and expanded. Then the hybridoma cell line was established. Cells were passaged in HT medium after HAT selection is completed (2-3 weeks).

Preparation and purification of McAbs to survivin and standard protein. Hybridoma cell lines (C6 and E6) secreting anti-survivin McAbs with high signals on ELISA were expanded as ascetic fluids in BALB/c mice. The McAbs were purified by protein-G affinity chromatography from the ascetic fluids. Antibody concentrations were determined by using the BCA protein assay kit. Our laboratory has already done experiments before comparing the newly generated antibodies with commercial antibodies. We have detected survivin expression in cancer by several methods such as IHC and western blot analysis, using the newly generated antibodies and the commercial antibody (an anti-survivin monoclonal antibody from Santa Cruz Biotechnology, Inc., Dallas, TX, USA) simultaneously. Results showed that the newly generated antibodies were comparable with the commercial antibody (22). Hence, our newly generated antibodies have been identified to be reliable. Recombinant human sequence survivin protein $\mathrm{MS}_{2}$-survivin produced by our laboratory was used as the standard protein (23). The standard series were prepared by diluting $\mathrm{MS}_{2}$-Survivin stock with dilution buffer to target values of $0,10,50,100,500,1,000 \mathrm{ng} / \mathrm{ml}$, assigning to $\mathrm{S} 0, \mathrm{~S} 1, \mathrm{~S} 2, \mathrm{~S} 3, \mathrm{~S} 4$ and $\mathrm{S} 5$, respectively.

Preparation of HRP-labeled antibody. Anti-survivin McAbs (C6, E6) were labeled with HRP, respectively. Briefly, purified McAbs were dialyzed against several changes of carbonate buffer [0.1 M sodium carbonate buffer $\left.\left(\mathrm{NaHCO}_{3} / \mathrm{Na}_{2} \mathrm{CO}_{3}\right)\right]$ $\mathrm{pH} 9.5$ at $4^{\circ} \mathrm{C}$ overnight. The HRP protein dissolved in deionized water at a concentration of $5 \mathrm{mg} / \mathrm{ml}$ was pretreated with $\mathrm{NaIO}_{4}$ stirring for $20 \mathrm{~min}$ at room temperature in dark, and then was dialyzed against $\mathrm{CH}_{3} \mathrm{COONa}(1 \mathrm{mmol} / 1$ sodium acetate buffer) $\mathrm{pH} 4.4$ at $4^{\circ} \mathrm{C}$ overnight. Equivalent pretreated McAbs and HRP solution were blended and incubated at room temperature for $2 \mathrm{~h}$ with gentle stirring in dark. Then $\mathrm{NaH}_{4} \mathrm{~B}$ was added, stirring at $4^{\circ} \mathrm{C}$ for $2 \mathrm{~h}$. The reaction solution was dialyzed against several changes of PBS buffer $(0.01 \mathrm{M}$ sodium phosphate, $0.15 \mathrm{M}$ sodium chloride, $\mathrm{pH} 7.4$ ) at $4^{\circ} \mathrm{C}$ overnight. After dialyzing, the reaction mixture was applied to a Sephacryl S-200 column to remove unlabeled HRP. The $\mathrm{HRP}$-conjugated McAbs were stored at $-20^{\circ} \mathrm{C}$ until use.

Preparation of biotinylated antibody. Anti-survivin McAbs $(\mathrm{C} 6$, E6) were coupled with biotin, respectively using a standard protocol. Briefly, $1 \mathrm{mg}$ of anti-survivin monoclonal antibody dissolved in $1 \mathrm{ml}$ of $0.1 \mathrm{~mol} / 1$ carbonate buffer $(\mathrm{pH} \mathrm{8.0)}$ was dialyzed against carbonate buffer ( $\mathrm{pH} 8.0)$ at $4^{\circ} \mathrm{C}$ for $2 \mathrm{~h} .1 \mathrm{mg}$ of NHSB was dissolved in $1 \mathrm{ml}$ of DMSO. $1 \mathrm{ml} \mathrm{McAbs} \mathrm{solution}$ was added into $120 \mu \mathrm{l}$ of NHS-D-biotin solution with gentle 
stirring and incubated at room temperature for $4 \mathrm{~h}$. Then $9.6 \mu \mathrm{l}$ of $1 \mathrm{~mol} / 1 \mathrm{NH}_{4} \mathrm{Cl}$ was added, stirring at room temperature for $10 \mathrm{~min}$. The reaction solution was dialyzed against several changes of PBS buffer ( $0.01 \mathrm{M}$ sodium phosphate, $0.15 \mathrm{M}$ sodium chloride, $\mathrm{pH} 7.4$ ) at $4^{\circ} \mathrm{C}$ to remove unlabeled biotin. The dialyzed biotinylated $\mathrm{McAbs}$ were stored at $-20^{\circ} \mathrm{C}$ until use.

ELISA procedure. E6 $(100 \mu 1,2.5 \mu \mathrm{g} / \mathrm{ml})$ was coated onto a 96-well microplate at $4^{\circ} \mathrm{C}$ overnight. After blocking with $200 \mu 15 \%$ skimmed milk in PBS for $1 \mathrm{~h}$ at $37^{\circ} \mathrm{C}$ and washing 3 times with PBST, $100 \mu 1$ survivin standards and urine samples were added into the wells. After incubating at $37^{\circ} \mathrm{C}$ for $1 \mathrm{~h}$ and washing 3 times, $100 \mu \mathrm{l} \mathrm{HRP-labeled} \mathrm{C6}$ was added to each well. The microplate was incubated at $37^{\circ} \mathrm{C}$ for $1 \mathrm{~h}$ and washed 3 times. Then substrate solution was added to the wells and every pore's absorption was determined at $450 \mathrm{~nm}$. McAbs (C6 and E6) used in this ELISA procedure have been identified to be reliable as mentioned above.

Microplate magnetic CLIA procedure. The immunoassay procedure of microplate magnetic CLIA in this study is displayed in Fig. 1 and the detailed steps were as follows: First, $50 \mu \mathrm{l}$ HRP-labeled anti-survivin McAb, $50 \mu 1$ biotinylated anti-survivin McAb and $20 \mu \mathrm{l}$ survivin standard solution were added into the micro-well and incubated for $20 \mathrm{~min}$ at $37^{\circ} \mathrm{C}$. After the sandwich reaction, $1 \mu 1$ streptavidin MPs were added to react with immunoassay reagents for another $10 \mathrm{~min}$ (capture time) at $37^{\circ} \mathrm{C}$. Subsequently, the separation procedure was carried out, during which the magnets attracted streptavidin MPs and any specific captured materials to the bottom of micro-wells. The micro-wells were washed with $200 \mu \mathrm{l}$ of washing solution three times after removing unwanted materials. Finally, $150 \mu \mathrm{l}$ of CL substrate was added and the relative light unit (RLU) was measured in the dark.

Human specimens collection and detection. All human specimens were obtained from Peking University Cancer Hospital. All of the cancer patients were diagnosed histopathologically and staged according to the tumor node metastasis (TNM) classification released by the American Joint Committee on Cancer (AJCC 7th edition, 2010). Healthy controls with a negative cystoscopy were chosen at the medical examination center. A total of 130 urine samples of bladder cancer patients and 113 urine samples of healthy controls were collected from January to July 2016. All urine samples were collected at the day and centrifuged immediately at 3,000 r/min for $5 \mathrm{~min}$, and the supernatant was aliquoted, and stored at $-40^{\circ} \mathrm{C}$ until detection. The samples were tested for survivin levels using the established method directly without any pretreatment. All patients and healthy controls were informed consent for participation in this study. The study was approved by the Ethics Committee of Peking University Cancer Hospital and Institute. All study procedures were in accordance with the Helsinki Declaration.

Data analysis. Standards and samples were measured, and CL intensity values were integrated. Standard curves were obtained by plotting the logarithm of CL intensity (in RLUs) against the logarithm of standard concentration and fitting to a linear equation. Student's t-test was used for the comparison of the variables between groups. Data was expressed as mean values \pm standard deviation. Enumeration data was expressed as percentages analyzing by $\chi^{2}$ test. A p-value of $<0.05$ was considered to be significant. Cutoff value was determined by the optimal Youden's index (sensitivity + specificity-1). All the statistical analysis was performed using the SPSS statistical software (SPSS for Mac, version 20).

\section{Results}

Determination of the proper antibody combination. The antibody pair used in this assay has been tested in a sandwiched ELISA assay. One of the two antibodies was labeled with HRP and the other was to be biotinylated. Since there were two possible combinations, the first development step was the selection of the optimal antibody combination. In order to test whether biotinylated E6 and HRP-labeled C6 or biotinylated C6 and HRP-labeled E6 combined better; three different concentrations $(10,100,1,000 \mathrm{ng} / \mathrm{ml})$ of the survivin standard and a negative control (dilution buffer) were analyzed under both combinations. Then the signal-to-background (S/B) ratio was calculated and compared for the determination of the better antibody combination. Student's t-test was used for data comparison. According to Fig. 2, HRP-labeled C6 and biotinylated E6 were determined as the proper antibody pair which providing a higher $\mathrm{S} / \mathrm{B}$ ratio $(\mathrm{P}<0.05)$.

Influence and optimization of immunoassay reagents. The immunoreaction reagent is an important parameter affecting the sensitivity and accuracy of immunoassay, especially in a sandwich immunoassay. In this experiment, the dilution ratios of HRP-labeled antibody and biotinylated antibody were studied and optimized. The HRP-labeled antibody and biotinylated antibody were diluted with dilution buffers to a series of dilution ratios with the standard survivin concentration of $100 \mathrm{ng} / \mathrm{ml}$. Data was analyzed using Student's t-test. As shown in Fig. 3, the RLUs increased when the dilution ratios of HRP-labeled antibody increased from 1:90,000 to 1:15,000 at all dilution ratios of the examined biotinylated antibody $(\mathrm{P}<0.05)$. As for the biotinylated antibody, the RLU was approximately a peak with the dilution ratio of $1: 18,000$ $(\mathrm{P}<0.05)$. Considering both the sensitivity and the assay cost, we selected the dilution ratios of 1:15,000 and 1:18,000 for HRP-labeled antibody and biotinylated antibody respectively.

\section{Influence and optimization of physicochemical parameters} Influence of immunoassay incubation time. Incubation time of the immunoreagents may have a direct effect on the sensitivity of the immunoassay. Incubation time from 10 to $60 \mathrm{~min}$ (10 min as the interval) was studied. As shown in Table I, RLUs increased with increasing reaction time, while $\mathrm{RLUS}_{1} / \mathrm{RLUS}_{0}$ (reflecting sensitivity) and RLUS RLUS $_{0}$ (reflecting linear range) increased with time up to $20 \mathrm{~min}$ and after $20 \mathrm{~min}$ the values tended to decrease. Based on all this and considering nonspecific absorption would improve with a longer incubation time, incubation time of 20 min was selected.

Influence of the volume of MPs. The quantity of streptavidin MPs was critical for the immunoassay system. The volumes of the MPs $(10 \mathrm{mg} / \mathrm{ml})$ were optimized from 0.2 to $2.0 \mu \mathrm{l}$. 

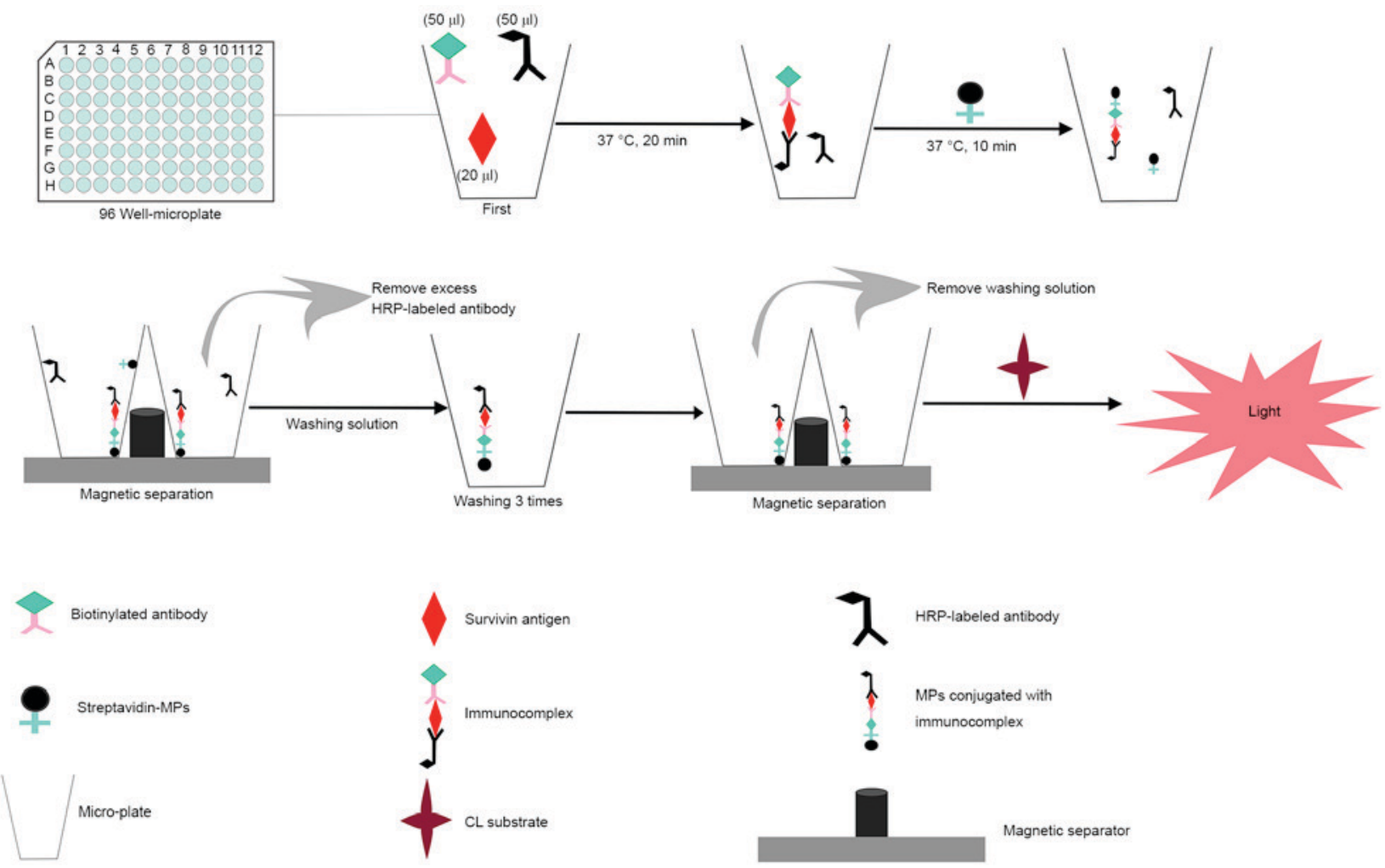

Figure 1. Schematic illustration of the established MPs-CLIA method. MPs, magnetic particles.

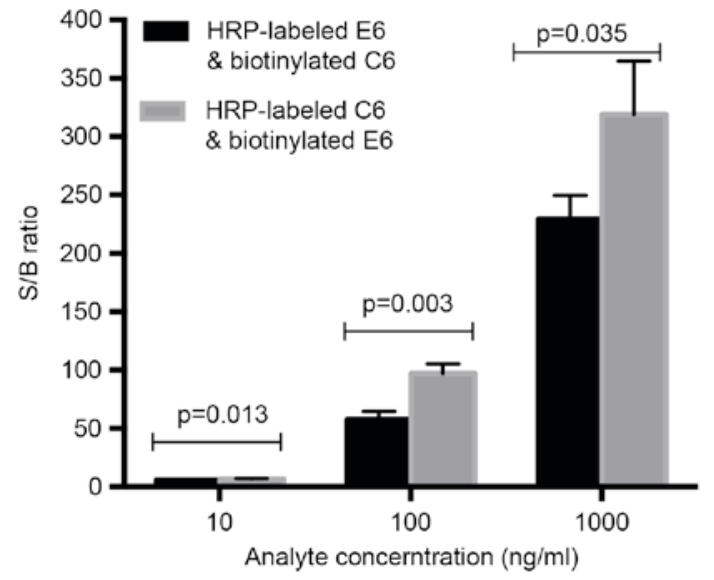

Figure 2. Determination of the best antibody pair. Detection methods: S/B ratio obtained for both antibody pairs, with 10,100 and $1,000 \mathrm{ng} / \mathrm{ml}$ of the survivin standards. RLU, relative light unit.

Student's t-test was used for data comparison. As shown in Fig. 4, the RLUs increased with the volume of MPs from 0.2 to $1.0 \mu \mathrm{l}$ and then decreased gradually as the volume increased from 1.0 to $2.0 \mu 1$. An excess of MPs might absorb the emitted light (24). Therefore the optimal volume of MPs was set to $1.0 \mu 1(\mathrm{P}<0.05)$.

Influence of capture time. In this experiment, MPs were used as the separation agent. After adding MPs, immunoassay regents were captured. Capture time from 10 to $60 \mathrm{~min}(10 \mathrm{~min}$ as the interval) was also explored to make clear its effect on the sensitivity of this immunoassay. As shown in Table II, RLUs

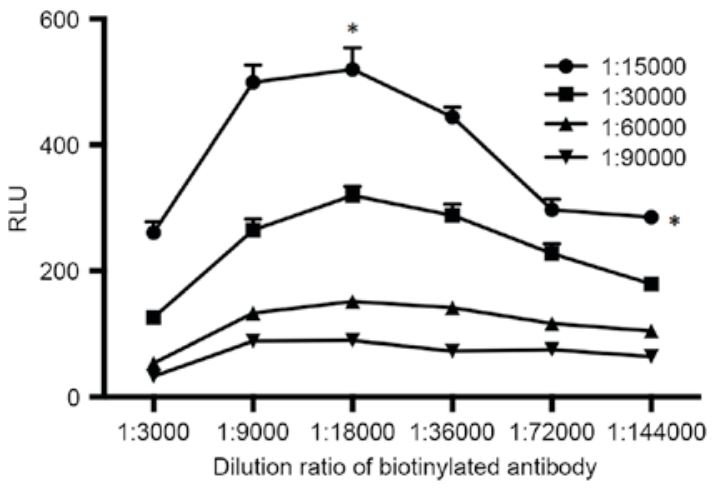

Figure 3. Influence of the dilution ratios of the HRP-labeled antibody and the biotinylated antibody. Detection conditions: the standard survivin concentration of $100 \mathrm{ng} / \mathrm{ml}$; room temperature; $1 \mu \mathrm{l}$ of streptavidin-coated MPs and $150 \mu \mathrm{l}$ of CL substrate. The four curves correspond to a series of dilution ratios of the HRP-labeled antibody. ${ }^{*} \mathrm{P}<0.05$. RLU, relative light unit; MPs, magnetic particles.

increased weakly with increasing capture time, meanwhile RLUS $_{1} /$ RLUS $_{0}$ (reflecting sensitivity) and RLUS $5 /$ RLUS $_{0}$ (reflecting linear range) tended to decrease as time gone by. Thus, capture time of $10 \mathrm{~min}$ was selected.

Influence of the volume of the CL substrate and chemiluminescence reaction time. The CL substrate was a pivotal factor related to the CL intensity and the sensitivity of the assay. In this experiment, the CL substrate volume from 0 to $200 \mu \mathrm{l}$ (25 $\mu \mathrm{l}$ as the interval) and the chemiluminescence reaction time from 10 to $60 \mathrm{~min}$ (10 min as the interval) were examined. Data was compared by Student's t-test. As shown in Fig. 5, the 
Table I. Effects of immunoassay incubation time.

\begin{tabular}{lccccc}
\hline \multirow{2}{*}{$\begin{array}{l}\text { Incubation } \\
\text { time (min) }\end{array}$} & \multicolumn{5}{c}{ RLU } \\
\cline { 2 - 6 } & $\mathrm{S} 0$ & $\mathrm{~S} 1$ & $\mathrm{~S} 5$ & $\mathrm{~S} 1 / \mathrm{S} 0$ & $\mathrm{~S} 5 / \mathrm{S} 0$ \\
\hline 10 & 4.439 & 20.063 & 997.43 & 4.519711647 & 224.6970038 \\
20 & 4.771 & 34.796 & 1182.4 & 7.293229931 & 247.8306435 \\
30 & 15.11 & 99.722 & 1234.9 & 6.599735275 & 81.72733289 \\
40 & 17.304 & 79.333 & 1338.2 & 4.584662506 & 77.3347203 \\
50 & 21.694 & 133 & 1341.2 & 6.13072739 & 61.82354568 \\
60 & 22.932 & 105.42 & 1400.9 & 4.597069597 & 61.08930752 \\
\hline
\end{tabular}

Detection conditions: The HRP-labeled antibody dilution ratio is 1:15,000; the biotinylated antibody dilution ratio is $1: 18,000,1 \mu 1$ of streptavidin-coated MPs, and $150 \mu 1$ of CL substrate. The capture time is $10 \mathrm{~min}$. RLU, relative light unit.

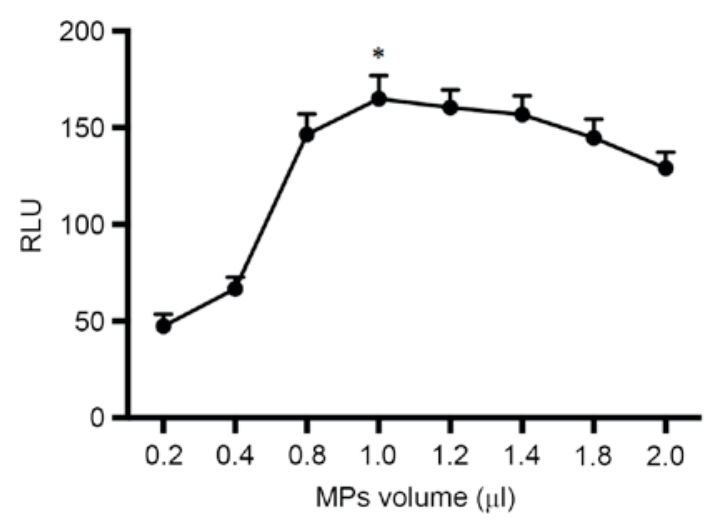

Figure 4. Optimization of the volume of MPs. Detection conditions: The standard survivin concentration is $50 \mathrm{ng} / \mathrm{ml}$; room temperature and $150 \mu \mathrm{l}$ of CL substrate; the HRP-labeled antibody dilution ratio is 1:15,000; the biotinylated antibody dilution ratio is $1: 18,000$. ${ }^{*} \mathrm{P}=0.01$. RLU, relative light unit; MPs, magnetic particles.

RLUs increased with increasing volume of CL substrate up to a maximum at $150 \mu \mathrm{l}$ and then gradually decreased $(\mathrm{P}<0.05)$. As to the chemiluminescence reaction time, RLUs decreased over time $(\mathrm{P}<0.05)$. Thus, $150 \mu \mathrm{l}$ of $\mathrm{CL}$ substrate and $10 \mathrm{~min}$ of chemiluminescence reaction time were chosen.

\section{Method evaluation}

Calibration curve and sensitivity. Under the optimal conditions, dose-response curve (Fig. 6) was obtained. By first obtaining the average RLU signals for 10 replicates of $S_{0}$ and then adding 2 standard deviations (SDs) into the dose-response curve the detection limit was calculated. The obtained detection limit for survivin was $0.83 \mathrm{ng} / \mathrm{ml}$.

Precision. In order to obtain the intra-assay precision, three different concentrations of standards were measured 10 times within one assay. Similarly, these standards were analyzed on 5 different days using the same protocol (2 replicates per run) to obtain the inter-assay variation. As shown in Table III, intra-assay and inter-assay CVs were $<8$ and $<11 \%$, respectively.

Linearity-dilution effect. The linearity-dilution effect was studied by selecting a certain human sample with relatively high concentration. This sample was then diluted to a series of concentrations with dilution buffer. The results were shown in Fig. 7.

Comparison with ELISA. Survivin levels of 60 urine samples of bladder cancer patients were determined simultaneously using ELISA and the newly established method. As can be seen in Fig. 8, two methods were compared and there was a good agreement with the correlation coefficient of 0.9860 $(\mathrm{P}<0.01)$.

\section{Sample analysis}

General data of groups. A total of 130 bladder cancer patients and 113 healthy controls were enrolled in the present study. Table IV summarized the general characterization of two groups $\left(\chi^{2}\right.$ test $)$.

Analysis of urine survivin levels between groups. Receiver operating characteristic (ROC) curve based on the detection of 130 bladder cancer patients and 113 healthy people was shown in Fig. 9. The area under the curve was 0.799 . When survivin concentration was $2.0884 \mathrm{ng} / \mathrm{ml}$, sensitivity and specificity were 86.9 and $61.9 \%$, respectively. We compared the urinary survivin levels between bladder cancer patients and healthy controls (Student's t-test). The urinary survivin levels were significantly higher in bladder cancer patients than in healthy controls $(\mathrm{P}<0.001)$. Table $\mathrm{V}$ and Fig. 10 gave the results of comparison and the scatter plot of survivin levels between groups.

Comparison of urine survivin levels in different clinicopathological categories of bladder cancer patients. Clinicalpathological features including age, gender, smoke, hypertension, metastasis stage, lymph node status, TNM stage, histological stage, tumor size, tumor thrombus and primary or not were obtained. We compared the urinary survivin levels between different clinicopathological categories of bladder cancer patients using Student's t-test. Results showed that among all the factors, urinary survivin levels associated with metastatic stage, histological stage and recurrence $(\mathrm{P}<0.01)$. The comparison results were summarized in Table VI. 
Table II. Effects of immunoassay capture time.

\begin{tabular}{lccccc}
\hline \multirow{2}{*}{$\begin{array}{l}\text { Capturing } \\
\text { time (min) }\end{array}$} & \multicolumn{5}{c}{ RLU } \\
\cline { 2 - 6 } & S0 & S1 & S5 & S1/S0 & S5/S0 \\
\hline 10 & 4.406 & 39.744 & 1176.4 & 9.020426691 & 266.9995461 \\
20 & 7.916 & 70.159 & 1234.9 & 8.862935826 & 156.0005053 \\
30 & 8.74 & 73.929 & 1338.2 & 8.458695652 & 153.1121281 \\
40 & 14.858 & 105.74 & 1341.2 & 7.116704805 & 90.26786916 \\
50 & 17.935 & 94.731 & 1400.9 & 5.281906886 & 78.10984109 \\
60 & 20.983 & 86.384 & 1524.4 & 4.116856503 & 72.64928752 \\
\hline
\end{tabular}

Detection conditions: The HRP-labeled antibody dilution ratio is 1:15,000; the biotinylated antibody dilution ratio is 1:18,000, $1 \mu 1$ of streptavidin-coated MPs, and $150 \mu \mathrm{l}$ of CL substrate. The incubation time of the first step is $20 \mathrm{~min}$. RLU, relative light unit

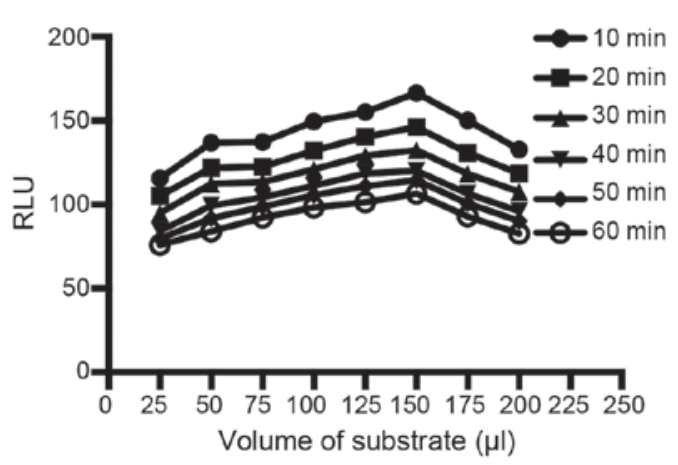

Figure 5. Influence of substrate volume and time required for enzyme-substrate incubation on RLU values. Detection conditions: a standard positive sample $(50 \mathrm{ng} / \mathrm{ml})$ was used to evaluate the effect; room temperature and $1 \mu \mathrm{l}$ of Streptavidin-coated MPs; the HRP-labeled antibody dilution ratio is 1:15,000; the biotinylated antibody dilution ratio is $1: 18,000$. The six plots correspond to a series of durations required for enzyme-substrate incubation (10,20,30,40,50 and $60 \mathrm{~min})$. RLU: " $\mathrm{P}<0.05$. RLU, relative light unit; MPs, magnetic particles.

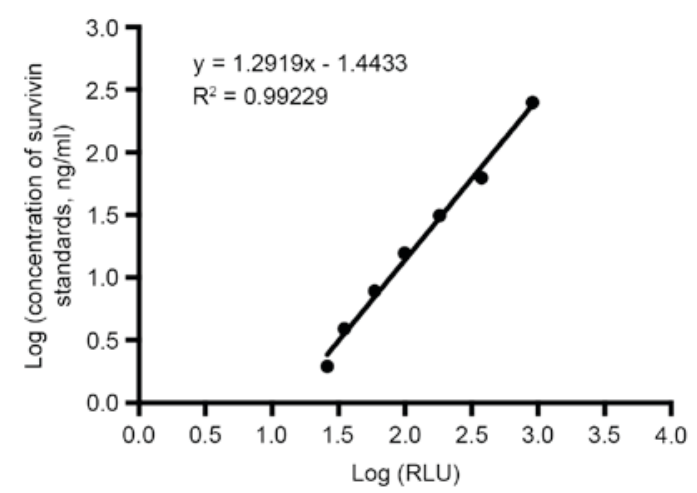

Figure 6. Calibration curve for survivin standards. The calibration curve was constructed under the optimized conditions and showed a detection range from 0.97 to $1,000 \mathrm{ng} / \mathrm{ml}$ with a detection limit of $0.83 \mathrm{ng} / \mathrm{ml}$. RLU, relative light unit.

\section{Discussion}

Survivin is expressed during fatal development and involved in blocking caspases (25-27) as well as favoring aberrant progression through mitosis (28). Studies have found that overexpression of survivin in human malignancies could be associated with carcinoma metastasis and progression (29). High expression of survivin in bladder cancer is associated with several unfavorable prognostic factors such as increasing recurrence rates, progression and resistance to therapy (30). Though a series of studies have evaluated urinary survivin as a biomarker for bladder cancer, the exact role of urinary survivin is still unclear partly due to the suboptimal measurements $(31,32)$.

Several methods have been used to detect survivin expression including IHC, real-time-PCR, Reverse transcription-polymerase chain reaction (RT-PCR) and ELISA (32-34). However, RT-PCR and Real-time PCR are costly which requires professional facilities. IHC is accurate while tissue specimens are difficult to get. Though ELISA is considered accurate and sensitive, it is to some content limited as time consuming with a bad uniformity. Here in this research, a new measurement was established for the detection of urinary survivin.

In the present study, a microplate magnetic CLIA was established for the analysis of urinary survivin levels. By combining magnetic separation with chemiluminescence detection system, this research first applied a novel sandwich immunoassay to the determination of urinary survivin. The dilution ratios of immunoreagents as well as physicochemical parameters were optimized during the method development.

With the established and refined measurement, 130 samples of bladder cancer patients and 113 samples of healthy controls were detected for urinary survivin levels. The results showed that urinary survivin levels of bladder cancer patients were significantly higher than that of healthy controls, which is consistent with some other studies $(13,19,35)$ and indicating urinary survivin as a potential biomarker for the diagnosis of bladder cancer. Besides, by analyzing the correlation of urinary survivin levels with clinicopathological factors, the currently study found that the urinary survivin levels were positively associated with metastatic stage, histological stage and recurrence, which is consistent with some studies $(19,32)$ while disaccord with another study (18).

Compared with ELISA, a main advantage of the novel measurement in this experiment is its rapidity. Besides, by 
Table III. Intra- and inter-assay variability for survivin.

\begin{tabular}{lccccccr}
\hline & \multicolumn{3}{c}{ Intra-assay } & & \multicolumn{3}{c}{ Inter-assay } \\
\cline { 2 - 3 } Sample no. & $\begin{array}{c}\text { Times of } \\
\text { replication }\end{array}$ & $\begin{array}{c}\text { Concentration } \\
(\mathrm{ng} / \mathrm{ml})\end{array}$ & $\begin{array}{c}\mathrm{CV} \\
(\%)\end{array}$ & & $\begin{array}{c}\text { Days of } \\
\text { replication }\end{array}$ & $\begin{array}{c}\text { Concentration } \\
(\mathrm{ng} / \mathrm{ml})\end{array}$ & $\begin{array}{c}\mathrm{CV} \\
(\%)\end{array}$ \\
\hline 1 & 10 & 331.5 & 0.7 & & 5 & 330.7 & 1.62 \\
2 & 10 & 128.76 & 3.7 & 5 & 127.83 & 7.87 \\
3 & 10 & 22.91 & 7.54 & 5 & 23.14 & 10.46 \\
\hline
\end{tabular}

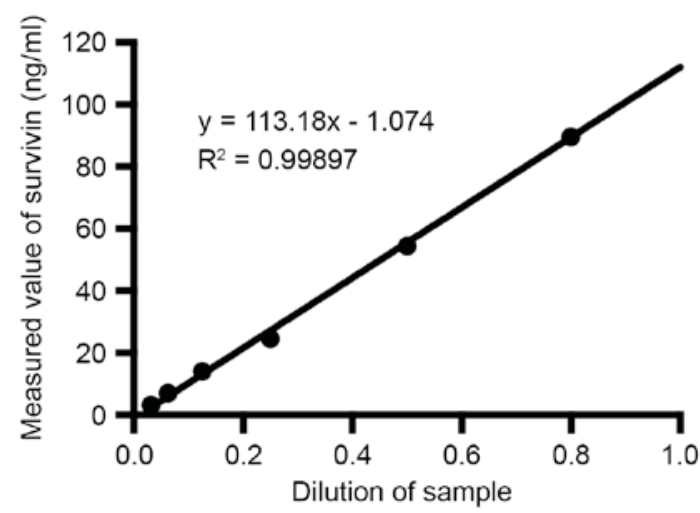

Figure 7. The linearity-dilution effect of the high concentration sample.

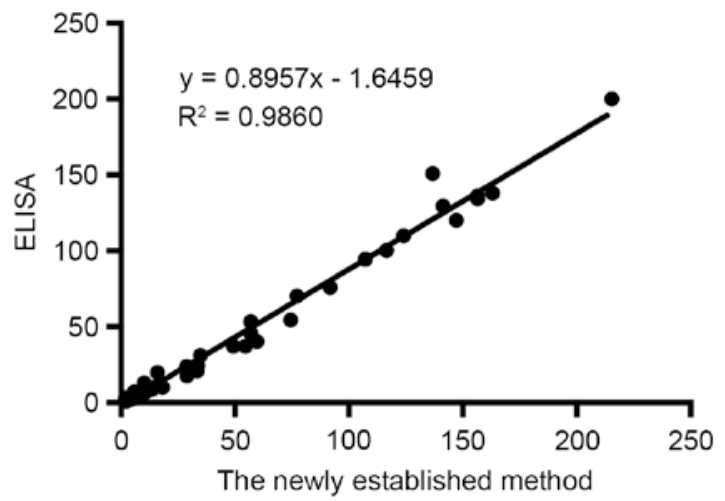

Figure 8. Correlation between urinary survivin levels measured by the newly established method and ELISA.

utilizing microplates, a high flux of analysis and a good uniformity are realized $(20,36)$. At the same time, the microplates were pre-coated with $1 \%(\mathrm{w} / \mathrm{v}) \mathrm{BSA}$ in PBS buffer to avoid the high non-specific absorption of the plates. The microplate magnetic technologies were rarely reported $(21,37,38)$ and even few applications were found for the detection of survivin. Here in this study, streptavidin MPs were used as separation reagents, combined with the magnetic separation device, greatly simplifying the separation procedure. Furthermore, the new measurement reduces the amount of immunoassay regents and the volume of samples, showing great potential in the future.

Meanwhile, it should be noted that this research has some limitations. On one hand, the use of MPs in this research
Table IV. General data of bladder cancer patients and healthy controls.

\begin{tabular}{llll}
\hline Variable & $\begin{array}{l}\text { Patients } \\
(\mathrm{n}=130)\end{array}$ & $\begin{array}{l}\text { Controls } \\
(\mathrm{n}=113)\end{array}$ & P-value \\
\hline $\begin{array}{l}\text { Gender, } \mathrm{n}(\%) \\
\text { Female }\end{array}$ & $36(27.7)$ & $38(33.6)$ & 0.331 \\
Male & $94(72.3)$ & $75(66.4)$ & \\
$\begin{array}{l}\text { Age, } \mathrm{n}(\%) \\
>62\end{array}$ & $74(56.9)$ & $73(64.6)$ & 0.239 \\
$\leq 62$ & $56(43.1)$ & $40(35.4)$ & \\
\hline
\end{tabular}

was expected to provide many more active binding sites and increase the sensitivity as well as facilitate larger linear range in the detection (39), but results were not positive. When the cutoff survivin level was $2.0884 \mathrm{ng} / \mathrm{ml}$, sensitivity and specificity were 86.9 and $61.9 \%$ respectively, not superior to some other reports of different methods $(18,32,40)$. This may be partly due to the heterogeneity between different studies as well as different cut-off values. While the complexity of urine components and variability of urine $\mathrm{pH}$ may be the main factor hinders the development of more sensitive methods $(41,42)$. On the other hand, the linearity-dilution effect was unstable and varied a lot between different samples using this method. This may be attributed to the imperfect diluent used in this research, which is unable to deal with the complexity of urine components.

The main objective of our study was the establishment of a novel immunoassay for urinary survivin detection; for this purpose urine sample of patients treated recently (from January 2016 to July 2016) in our hospital were collected. It is too close to track the long-term prognosis information of these patients. Since long-term prognosis information of patients is important for clinical course evaluation, our study is limited to some extent considering the deficiency of the information. This study showed that urinary survivin level was correlated with metastatic stage, histological stage and recurrence, which implied survivin as a potential marker of disease progression. It could be better if we could obtain the long-term prognosis information to further evaluate the value of survivin. In the next years, we will follow-up the bladder cancer patients included in this study to do further investigation according to your suggestion. Moreover, we established a new method 
Table V. Comparison of survivin levels between groups.

\begin{tabular}{|c|c|c|c|}
\hline \multirow[b]{2}{*}{ Group } & \multirow[b]{2}{*}{ Number } & Survivin levels (ng/ml) & \multirow[b]{2}{*}{ P-value } \\
\hline & & Mean \pm SD & \\
\hline Patients & 130 & $23.1372 \pm 41.73024$ & $<0.001$ \\
\hline Controls & 113 & $3.4419 \pm 4.85624$ & \\
\hline
\end{tabular}

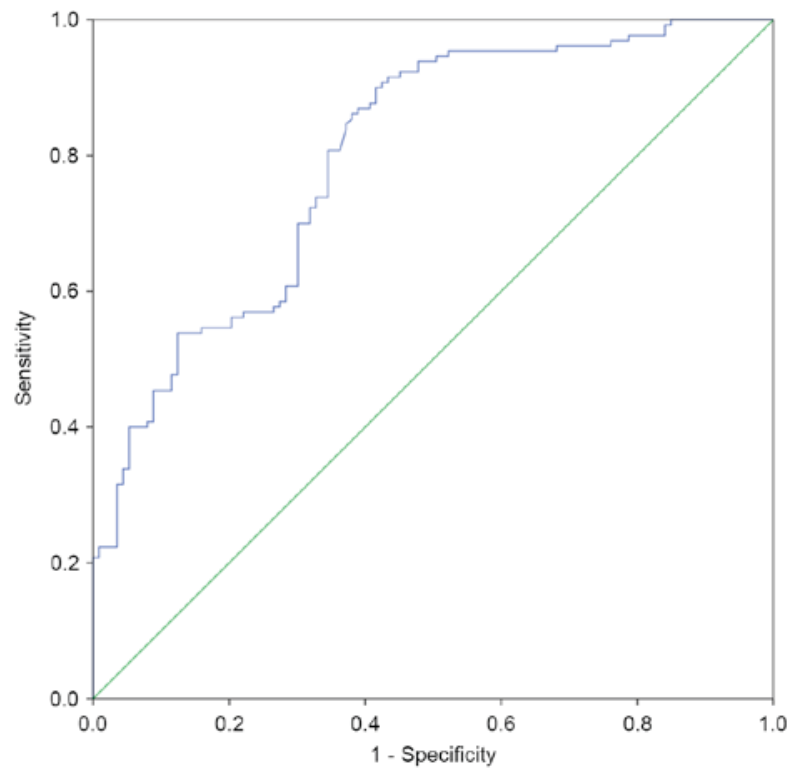

Figure 9. ROC curve. Survivin levels of urine samples were detected among healthy individuals and bladder cancer patients. ROC, receiver operating characteristic.

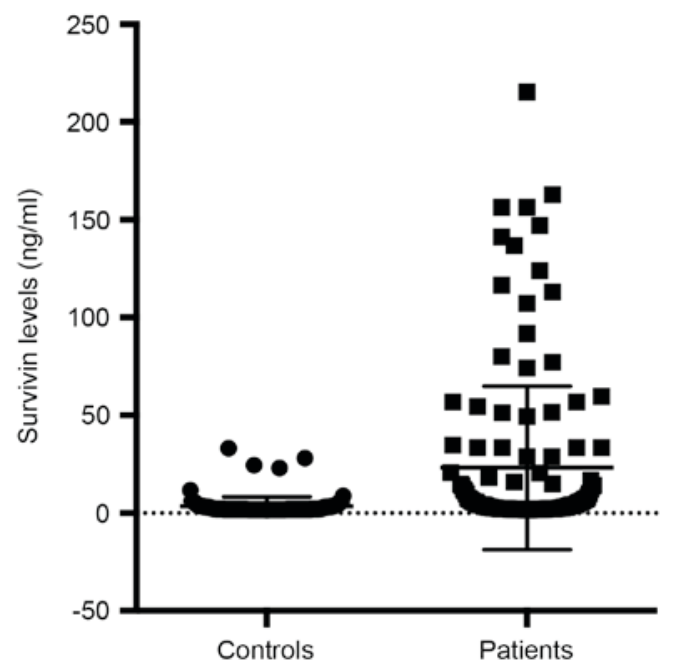

Figure 10. Survivin levels in healthy controls and bladder cancer patients. The urine of 113 healthy controls and 130 bladder cancer patients were detected.

and compared it with ELISA, while it is not the end. There are other methods for the evaluation of survivin levels such as methods for mRNA detection and IHC $(31,43)$. Though we have obtained data of these methods from other papers, it is not so accurate considering sample differences (31,43-45).
Table VI. Comparison of survivin levels in different clinicopathological categories of bladder cancer patients.

\begin{tabular}{|c|c|c|c|}
\hline \multirow{2}{*}{$\begin{array}{l}\text { Clinicopathological } \\
\text { characteristic }\end{array}$} & & $\begin{array}{c}\text { Survivin } \\
\text { levels }(\mathrm{ng} / \mathrm{ml})\end{array}$ & \multirow[b]{2}{*}{ P-value } \\
\hline & Number & Mean \pm SD & \\
\hline Age (years) & & & 0.192 \\
\hline$>62$ & 74 & $27.10 \pm 47.36$ & \\
\hline$\leq 62$ & 56 & $17.90 \pm 32.53$ & \\
\hline Gender & & & 0.83 \\
\hline Female & 36 & $24.41 \pm 38.55$ & \\
\hline Male & 94 & $22.65 \pm 43.07$ & \\
\hline Smoke & & & 0.515 \\
\hline Yes & 56 & $20.34 \pm 42.01$ & \\
\hline No & 72 & $25.23 \pm 42.08$ & \\
\hline Hypertension & & & 0.995 \\
\hline Yes & 45 & $22.97 \pm 43.30$ & \\
\hline No & 84 & $22.92 \pm 41.29$ & \\
\hline Metastatic stage & & & $<0.01$ \\
\hline M1 & 108 & $51.88 \pm 50.78$ & \\
\hline M0 & 22 & $17.28 \pm 37.27$ & \\
\hline Lymph node status & & & 0.058 \\
\hline Positive & 19 & $39.91 \pm 43.70$ & \\
\hline Negative & 111 & $20.27 \pm 40.90$ & \\
\hline Histological Stage & & & $<0.01$ \\
\hline G3 & 63 & $33.14 \pm 48.89$ & \\
\hline G1/G2 & 54 & $9.15 \pm 13.95$ & \\
\hline Size (cm) & & & 0.768 \\
\hline$\geq 3$ & 28 & $15.80 \pm 26.97$ & \\
\hline$<3$ & 59 & $18.10 \pm 36.70$ & \\
\hline Tumor thrombus & & & 0.636 \\
\hline Visible & 16 & $18.48 \pm 23.11$ & \\
\hline Invisible & 114 & $23.79 \pm 43.74$ & \\
\hline Recurrence & & & $<0.01$ \\
\hline Primary & 91 & $12.58 \pm 31.11$ & \\
\hline Recurrent & 39 & $47.77 \pm 52.25$ & \\
\hline TNM stage & & & 0.063 \\
\hline I-II & 94 & $18.59 \pm 39.27$ & \\
\hline III-IV & 36 & $35.02 \pm 46.05$ & \\
\hline
\end{tabular}

TNM, tumor node metastasis.

Therefore it is significant for us to collect more specimens and perform different methods to make better comparisons in the future.

This research implies urinary survivin as a potential tumor marker of metastasis, progression and recurrence in addition to diagnosis for bladder cancer with the novel established method. While considering the small number of patients in this study, a larger series of samples and further studies are needed in order to understand the role of survivin 
in bladder cancer better. Besides, since the molecular mechanism of bladder cancer is complicated, it may be much more predictive to combine other urinary markers with survivin $(46,47)$. Last but not least, the method itself is not perfect given the unsatisfactory sensitivity and linear range. Considering the complexity of urine matrix (48), it is difficult to develop immunoassays with good performance for urinary biomarkers. Therefore much more work should be done to explore a better measurement for urinary survivin detection based on this research.

\section{References}

1. Youssef RF and Lotan Y: Predictors of outcome of non-muscle-invasive and muscle-invasive bladder cancer. ScientificWorldJournal 11: 369-381, 2011.

2. Babjuk M,Böhle A, Burger M,Capoun O, Cohen D, Compérat EM, Hernández V, Kaasinen E, Palou J, Rouprêt M, et al: EAU guidelines on non-muscle-invasive urothelial carcinoma of the bladder: Update 2016. Eur Urol 71: 447-461, 2017.

3. Lokeshwar VB, Habuchi T, Grossman HB, Murphy WM, Hautmann SH, Hemstreet GP III, Bono AV, Getzenberg RH, Goebell P, Schmitz-Dräger BJ, et al: Bladder tumor markers beyond cytology: International consensus panel on bladder tumor markers. Urology 66 (6 Suppl 1): S35-S63, 2005.

4. Frantzi M, Latosinska A, Flühe L, Hupe MC, Critselis E, Kramer MW, Merseburger AS, Mischak $\mathrm{H}$ and Vlahou A: Developing proteomic biomarkers for bladder cancer: Towards clinical application. Nat Rev Urol 12: 317-330, 2015.

5. Gogalic S, Sauer U, Doppler S and Preininger C: Bladder cancer biomarker array to detect aberrant levels of proteins in urine. Analyst 140: 724-735, 2015.

6. Kamat AM, Hegarty PK, Gee JR, Clark PE, Svatek RS, Hegarty N, Shariat SF, Xylinas E, Schmitz-Dräger BJ, Lotan Y, et al: ICUD-EAU International consultation on bladder cancer 2012: Screening, diagnosis, and molecular markers. Eur Urol 63: 4-15, 2013.

7. Nisman B, Yutkin V, Peretz T, Shapiro A, Barak V and Pode D: The follow-up of patients with non-muscle-invasive bladder cancer by urine cytology, abdominal ultrasound and urine CYFRA 21-1: A pilot study. Anticancer Res 29: 4281-4285, 2009.

8. Jäger T, Tschirdewahn S, Vom Dorp F, Piechotta G, Rübben H and Szarvas T: Siliconchiptechnology-based MMP-7 analysis in urine: An option for preoperative identification of lymph node metastasis in bladder cancer. Urologe A 52: 853-858, 2013.

9. Altieri DC: Survivin in apoptosis control and cell cycle regulation in cancer. Prog Cell Cycle Res 5: 447-452, 2003.

10. Uren AG, Wong L, Pakusch M, Fowler KJ, Burrows FJ, Vaux DL and Choo KH: Survivin and the inner centromere protein INCENP show similar cell-cycle localization and gene knockout phenotype. Curr Biol 10: 1319-1328, 2000.

11. Giodini A, Kallio MJ, Wall NR, Gorbsky GJ, Tognin S, Marchisio PC, Symons M and Altieri DC: Regulation of microtubule stability and mitotic progression by survivin. Cancer Res 62: 2462-2467, 2002.

12. Zaffaroni N, Pennati M and Daidone MG: Survivin as a target for new anticancer interventions. J Cell Mol Med 9: 360-372, 2005.

13. Spaulding B, Pan D, Ghadersohi A, Nielsen G, Jensen S Gellert F, Ling X, Zhang M, Black A and Li F: Characterization of the 12C4 survivin monoclonal antibody and insight into the expression of survivin in human adult tissues. Histopathology 49 : 622-633, 2006

14. Muschol-Steinmetz C, Friemel A, Kreis NN, Reinhard J, Yuan J and Louwen F: Function of survivin in trophoblastic cells of the placenta. PLoS One 8: e73337, 2013

15. Weikert S, Christoph F, Schrader M, Krause H, Miller K and Müller M: Quantitative analysis of survivin mRNA expression in urine and tumor tissue of bladder cancer patients and its potential relevance for disease detection and prognosis. Int J Cancer 116: 100-104, 2005.

16. Karam JA, Lotan Y, Ashfaq R, Sagalowsky AI and Shariat SF: Survivin expression in patients with non-muscle-invasive urothelial cell carcinoma of the bladder. Urology 70: 482-486, 2007.
17. Margulis V, Lotan Y and Shariat SF: Survivin: A promising biomarker for detection and prognosis of bladder cancer. World J Urol 26: 59-65, 2008.

18. Li X, Wang Y, Xu J and Zhang Q: Sandwich ELISA for detecting urinary survivin in bladder cancer. Chin J Cancer Res 25: 375-381, 2013.

19. Srivastava AK, Singh PK, Srivastava K, Singh D, Dalela D, Rath SK, Goel MM and Brahma Bhatt ML: Diagnostic role of survivin in urinary bladder cancer. Asian Pac J Cancer Prev 14: 81-85, 2013.

20. Schneider C, Schöler HF and Schneider RJ: Direct sub-ppt detection of the endocrine disruptor ethinylestradiol in water with a chemiluminescence enzyme-linked immunosorbent assay. Analyt Chim Acta 551: 92-97, 2005.

21. Gundersen SG, Haagensen I, Jonassen TO, Figenschau KJ, de Jonge $\mathrm{N}$ and Deelder AM: Magnetic bead antigen capture enzyme-linked immunoassay in microtitre trays for rapid detection of schistosomal circulating anodic antigen. J Immunol Methods 148: 1-8, 1992.

22. Chen D, Xu J and Zhang Q: Detection of survivin expression in bladder cancer and renal cell carcinoma with its specific monoclonal antibodies. Oncology Reports In Press.

23. Wang Y, Zhang QY and Wang YM: Cloning of survivin gene and preparation its monoclonal antibodies as well as checking survivin expression in liver carcinoma cells. Chinese Journal of Laboratory Medicine, 2006.

24. Li Z, Zhang Q, Zhao L, Li Z, Hu G, Lin J and Wang S: Micro-plate magnetic chemiluminescence immunoassay and its applications in carcinoembryonic antigen analysis. Sci China Chem 53: 812-819, 2010

25. Herman MP, Svatek RS, Lotan Y, Karakiewizc PI and Shariat SF: Urine-based biomarkers for the early detection and surveillance of non-muscle invasive bladder cancer. Minerva Urol Nefrol 60: 217-235, 2008.

26. Budman LI, Kassouf W and Steinberg JR: Biomarkers for detection and surveillance of bladder cancer. Can Urol Assoc J 2: 212-221, 2008

27. Domnanich P, Sauer U, Pultar J and Preininger C: Protein microarray for the analysis of human melanoma biomarkers. Sensors Actuators B Chem 139: 2-8, 2009.

28. Li F and Ling X: Survivin study: An update of "what is the next wave'? J Cell Physiol 208: 476-486, 2006.

29. Eissa S, Shabayek MI, Ismail MF, El-Allawy RM and Hamdy MA: Diagnostic evaluation of apoptosis inhibitory gene and tissue inhibitor matrix metalloproteinase- 2 in patients with bladder cancer. IUBMB Life 62: 394-399, 2010.

30. Qin C, Cao Q, Li P, Ju X, Wang M, Chen J, Wu Y, Meng X, Zhu J, Zhang $\mathrm{Z}$, et al: Functional promoter $-31 \mathrm{G}>\mathrm{C}$ variant in survivin gene is associated with risk and progression of renal cell cancer in a Chinese population. PLoS One 7: e28829, 2012.

31. Jeon C, Kim M, Kwak C, Kim HH and Ku JH: Prognostic role of survivin in bladder cancer: A systematic review and meta-analysis. PLoS One 8: e76719, 2013.

32. Shariat SF, Casella R, Khoddami SM, Hernandez G, Sulser T, Gasser TC and Lerner SP: Urine detection of survivin is a sensitive marker for the noninvasive diagnosis of bladder cancer. J Urol 171: 626-630, 2004.

33. Kenney DM, Geschwindt RD, Kary MR, Linic JM, Sardesai NY and Li ZQ: Detection of newly diagnosed bladder cancer, bladder cancer recurrence and bladder cancer in patients with hematuria using quantitative rt-PCR of urinary survivin. Tumour Biol 28: 57-62, 2007.

34. Moussa O, Abol-Enein H, Bissada NK, Keane T, Ghoneim MA and Watson DK: Evaluation of survivin reverse transcriptase-polymerase chain reaction for noninvasive detection of bladder cancer. J Urol 175: 2312-2316, 2006.

35. Abd El-Hakim TF, El-Shafie MK, Abdou AG, Azmy RM, El-Naidany SS and Badr El-Din MO: Value of urinary survivin as a diagnostic marker in bladder cancer. Anal Quant Cytopathol Histpathol 36: 121-127, 2014.

36. Zhao L, Lin JM, Li Z and Ying X: Development of a highly sensitive, second antibody format chemiluminescence enzyme immunoassay for the determination of $17 \beta$-estradiol in wastewater. Anal Chim Acta 558: 290-295, 2006

37. Cudjoe KS, Hagtvedt $\mathrm{T}$ and Dainty R: Immunomagnetic separation of Salmonella from foods and their detection using immunomagnetic particle (IMP)-ELISA. Int J Food Microbiol 27: 11-25, 1995.

38. Yu H, Ahmed H and Vasta GR: Development of a magnetic microplate chemifluorimmunoassay for rapid detection of bacteria and toxin in blood. Anal Biochem 261: 1-7, 1998 
39. Zhang Q, Wang X, Li Z and Lin JM: Evaluation of alpha-fetoprotein (AFP) in human serum by chemiluminescence enzyme immunoassay with magnetic particles and coated tubes as solid phases. Anal Chim Acta 631: 212-217, 2009.

40. Wang H, Xi X, Kong X, Huang G and Ge G: The expression and significance of survivin mRNA in urinary bladder carcinomas. J Cancer Res Clin Oncol 130: 487-490, 2004.

41. $\mathrm{Wu} \mathrm{J}$, Chen YD and Gu W: Urinary proteomics as a novel tool for biomarker discovery in kidney diseases. J Zhejiang Univ Sci B 11: 227-237, 2010.

42. Fichorova RN, Richardson-Harman N, Alfano M, Belec L, Carbonneil C, Chen S, Cosentino L, Curtis K, Dezzutti CS, Donoval B, et al: Biological and technical variables affecting immunoassay recovery of cytokines from human serum and simulated vaginal fluid: A multicenter study. Anal Chem 80: 4741-4751, 2008.

43. Johnen G, Gawrych K, Bontrup H, Pesch B, Taeger D, Banek S, Kluckert M, Wellhäußer H, Eberle F, Nasterlack M, et al: Performance of survivin mRNA as a biomarker for bladder cancer in the prospective study UroScreen. PLoS One 7: e35363, 2012.

44. Horstmann M, Bontrup H, Hennenlotter J, Taeger D, Weber A, Pesch B, Feil G, Patschan O, Johnen G, Stenzl A and Brüning T: Clinical experience with survivin as a biomarker for urothelial bladder cancer. World J Urol 28: 399-404, 2010
45. Sun YW, Xuan Q, Shu QA, Wu SS, Chen H, Xiao J, Xiang P, Zhu YP, Wang FL and Zhao ST: Correlation of tumor relapse and elevated expression of survivin and vascular endothelial growth factor in superficial bladder transitional cell carcinoma. Genet Mol Res 12: 1045-1053, 2013.

46. Karam JA, Lotan Y, Karakiewicz PI, Ashfaq R, Sagalowsky AI, Roehrborn CG and Shariat SF: Use of combined apoptosis biomarkers for prediction of bladder cancer recurrence and mortality after radical cystectomy. Lancet Oncol 8: 128-136, 2007.

47. Als AB, Dyrskjøt L, von der Maase H, Koed K, Mansilla F, Toldbod HE, Jensen JL, Ulhøi BP, Sengeløv L, Jensen KM and Orntoft TF: Emmprin and survivin predict response and survival following cisplatin-containing chemotherapy in patients with advanced bladder cancer. Clin Cancer Res 13: 4407-4414, 2007.

48. Adachi J, Kumar C, Zhang Y, Olsen JV and Mann M: The human urinary proteome contains more than 1500 proteins, including a large proportion of membrane proteins. Genome Biol 7: R80, 2006. 